\title{
COLORECTAL RESECTIONS - CLINICAL AND IMMUNOLOGICAL RESULTS
}

\author{
Vasil Kyosev ${ }^{1}$, Elena Vikentieva ${ }^{2}$, Dora Popova ${ }^{2}$, Rositsa Vladimirova ${ }^{2}$, \\ Ventsislav Mutafchiyski ${ }^{1}$, Krasimir Vasilev ${ }^{1}$, Plamen Ivanov ${ }^{1}$, Grigor Grigorov ${ }^{1}$, \\ Georgi Kotashev ${ }^{1}$, Georgi Popivanov ${ }^{1}$, Vasilena Hristova ${ }^{1}$, Hristo Petrov ${ }^{1}$ \\ ${ }^{1}$ Clinic of Endoscopic, Endocrine surgery and Coloproctology, \\ Military Medical Academy - Sofia \\ ${ }^{2}$ Department of Clinical Immunology, Military Medical Academy - Sofia
}

\begin{abstract}
INTRODUCTION: Surgery induces a generalized state of postoperative immunosuppression responsible for a lot of complications in the postoperative period. The magnitude and the type of the intraoperative injury depend on the extent and duration of postoperative immune suppression. This study compared clinical outcomes and immune changes after minimally invasive and open colorectal resections in patients with colorectal cancer (CRC).

MATERIAL AND METHODS: The study included 40 patients with CRC who underwent colorectal resections in our clinic last year. Twenty one of them, with a mean age of 64.8 years (49-86), underwent minimally invasive surgery. The remaining 19 patients, with a mean age of 66.2 years (56-84), underwent conventional surgery. Blood tests were performed 24 hours prior to surgery, and 24 hours and 7 days after surgery. The analysis included full blood count, total protein, albumin and markers of inflammation (CRP, ESR, nand fibrinogen). T- (CD3+), B- (CD19+) and NK-cell lymphocyte populations were studied by means of flow cytometry, as well as activation of leukocytes, according to the expression of HLA-DR, CD38, CD279, CD163 and some clinical parameters. All data were analyzed using SPSS version 21.

RESULTS: There was no significant difference in the preoperative results between the minimally invasive group and the conventional group. 24 hours after surgery there were significant decrease in lymphocyte percentages and increased leukocyte count, granulocyte percentages and CRP levels in the conventional group. This ratio maintained for 7 days after surgery. Activated monocyte (CD 163+), total protein and albumin, eosinophiles, percentage of monocytes, lymphocytes and NKT-cells (CD3+ CD16/CD56+) had a significant decrease in the conventional group compared with the minimally invasive group in the first postoperative day.

CONCLUSIONS: Minimally invasive colorectal cancer resection is a technically feasible option, with comparable results in terms of oncologic clearance, lesser degrees of tissue injury, surgical metabolic stress, and immunosuppressive response to conventional open surgery. Patients undergoing minimally invasive resections demonstrated improved clinical recovery and shorter hospital stay than patients undergoing open surgery.
\end{abstract}

Keywords: minimally invasive surgery, postoperative immunosuppression, surgical metabolic stress

Address for correspondence:

Vasil Kyosev

3 Georgi Sofiyski Blvd,

1606 Sofia, Bulgaria

e-mail:dr_kyosev@abv.bg

Received: February 19, 2016

Accepted: March 7, 2016

Scripta Scientifica Medica, vol. 48, No. 1, 2016, pp. 43-49

Copyright (c) Medical University of Varna 


\section{INTRODUCTION}

Colorectal cancer (CRC) is the third most frequently diagnosed malignant disease and the fourth most common cause of cancer-related death worldwide $(2,3)$. Curative treatment of CRC relies principally on surgical resection, supported by adjuvant chemotherapy, radiotherapy, and/ or immunotherapy. Open abdominal surgery (OS) remains the predominant approach internationally; however, midline wound and peritoneal damage are associated with significant postoperative pain and longer hospital stay (4-6).

Over the past decade the surgical treatment for colorectal cancer has been revolutionized with the introduction of new minimally invasive techniques. These techniques have become integral to the general surgical practice, with the advantages over open surgery of an earlier return to normal activity and better esthetic outcomes demonstrated for a range of procedures $(1,7)$. Minimally invasive colorectal surgery involves inserting laparoscopic instruments through several ports in the abdominal wall to accomplish the same oncologic resection goals. The tumor is usually removed through an abdominal incision, the length of which depends on the size of the tumor $(1,8)$.

The trauma of surgery evokes a variety of physiologic and immunologic alterations that should contribute to host defense. The magnitude and the type of the intraoperative injury depend on the extent and duration of the postoperative immune suppression (9). However, an exaggerated response to injury may result in immunosuppression and lead to significant postoperative morbidity and mortality. Decreased postoperative pain and speedy functional recovery of minimally invasive operated patients may be attributable to the reduced inflammatory response and minimal immunosuppression $(10,11)$.

This study compared clinical outcomes and immune changes after minimally invasive and open colorectal resections in patients with colorectal cancer (CRC).

\section{METHODS}

The study included 40 patients with CRC who underwent colorectal resections in our clinic last year. Twenty one of them $(\mathrm{CRCm})$ underwent minimally invasive surgery, 12 men (30\%) and 9 women $(22.5 \%)$, the ratio between them being $1.3 / 1$, with a mean age of 64.8 years (range: $49-86)$. The remaining 19 patients (CRCk) underwent conventional surgery, 10 men (25\%) and 9 women (22.5\%), the ratio between them being 1.1/1, with a mean age of 66.1 years (range: 56-84) (Fig. 1). Most of the patients in the two groups were between 55 and 75 years of age (Fig. 2).

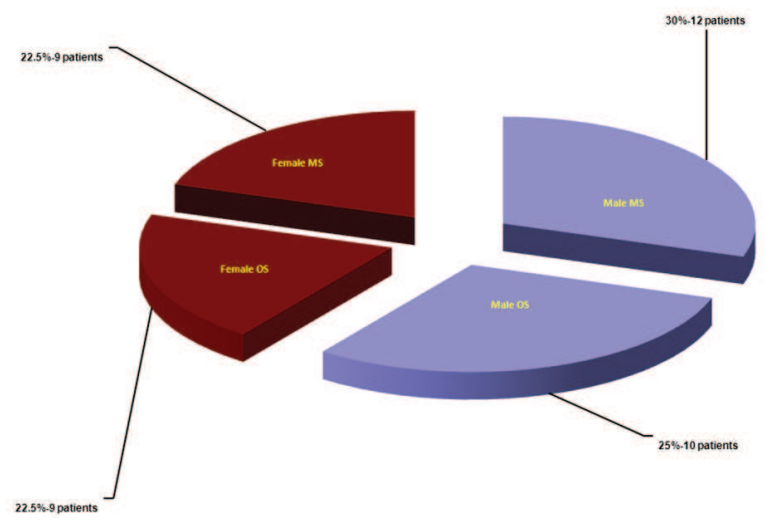

Figure 1. Distribution by gender of the patients in two CRC groups

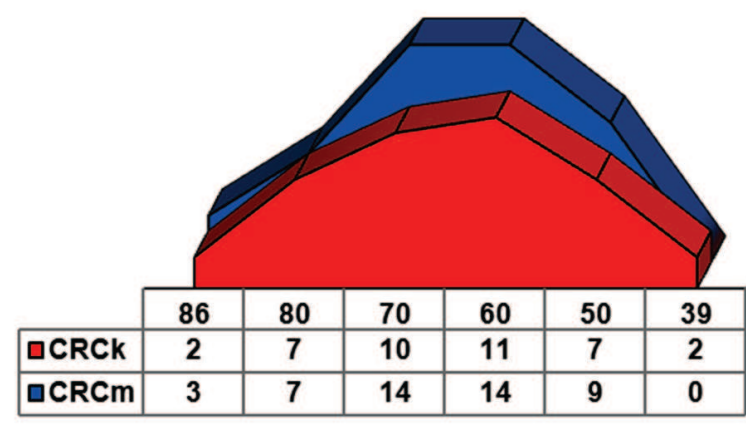

Figure 2. Distribution by age of the patients in two CRC groups

Twenty one patients had rectal carcinoma (14 men and 7 women) and nineteen had colon carcinoma (8 men and 11 women). Curative resection was performed in all cases. The disease was staged according to the TNM original classification, $5^{\text {th }}$ edition.

The distribution by localization of the tumor along the length of the colon/rectum, T- disease stage and type of surgical approach among the patients in our study is shown in Tabl. 1 .

The postoperative follow-up of each patient included blood loss, duration of operation, intravenous 
Vasil Kyosev, Elena Vikentieva, Dora Popova et al.

Table 1. Distribution by localization of the tumor, T-stage and type of surgical approach in CRC groups

\begin{tabular}{|c|c|c|c|c|c|}
\hline T-stage & $\mathrm{T} 1$ & $\mathrm{~T} 2$ & T3 & $\mathrm{T} 4$ & Total \\
\hline Patients & $\mathrm{n}=2$ & $\mathrm{n}=8$ & $n=22$ & $\mathrm{n}=8$ & $\mathrm{n}=40$ \\
\hline Men with rectal localization (Open Surgery) & - & 1 & 4 & 1 & 6 \\
\hline Men with rectal localization (Min. Surgery) & - & 2 & 4 & 2 & 8 \\
\hline Men with colon localization (Open.Surgery) & - & 1 & 2 & 1 & 4 \\
\hline Men with colon localization (Min. Surgery) & - & 1 & 3 & - & 4 \\
\hline Women with rectal localization (Open Surgery) & 1 & 2 & 2 & - & 5 \\
\hline Women with rectal localization (Min. Surgery) & - & - & 2 & - & 2 \\
\hline Women with colon localization (Open Surgery) & 1 & - & 2 & 1 & 4 \\
\hline Women with colon localization (Min. Surgery) & - & 1 & 3 & 3 & 7 \\
\hline
\end{tabular}

intake (crystalloid, colloid, antibiotics and blood units), drainage removal, re-gained use of bowels, nutrition supply, walking after surgery, hospital stay.

Blood samples were taken in the morning, 2 hours prior to surgery and 24 hours, and 7 days after surgery. The analysis included full blood count, serum protein levels (total protein, albumin), and markers of inflammation (CRP, ESR, fibrinogen). T(CD3+), B- (CD19+), and NK-cells, lymphocyte populations were studied by means of flow cytometry, as well as activation of leukocytes, according to the expression of HLA-DR, CD38, CD279, and CD163. SPSS.v21. was used to manage patient data and to perform statistical analyses. For significance of the results we accepted $\mathrm{p}<0.05$.

\section{RESULTS}

There was a significant difference between minimally invasive and conventional group operating times, although CRCm times were significantly shorter. Blood loss and intraoperative intravenous intake (crystalloid, colloid and antibiotics) were significantly less in patients undergoing minimally invasive resection, than in patients with open resection (Fig. 3).

Patients who underwent minimally invasive resection regained use of their bowels, walking after surgery, and had their drainage removed significant-

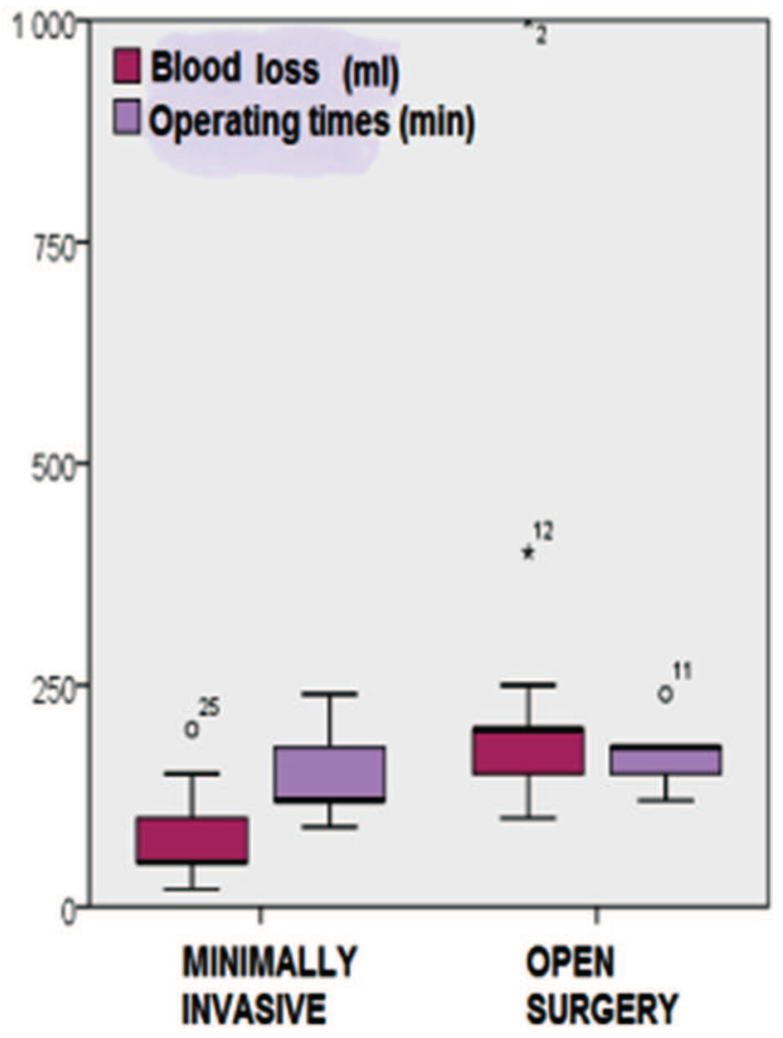

Figure 3. Blood loss and operative time in minimally invasive and open surgery group.

Table 2. Statistical comparison of clinical parameters in minimally invasive and open surgery group

\begin{tabular}{l|c|c|ccc|crc} 
Index & $\begin{array}{c}\text { Operating } \\
\text { times }\end{array}$ & $\begin{array}{c}\text { Blood } \\
\text { loss }\end{array}$ & $\begin{array}{c}\text { Intravenous } \\
\text { intake }\end{array}$ & $\begin{array}{c}\text { Walking } \\
\text { after } \\
\text { surgery }\end{array}$ & $\begin{array}{c}\text { Regained } \\
\text { use of } \\
\text { bowels }\end{array}$ & $\begin{array}{c}\text { Nutrition } \\
\text { supply }\end{array}$ & $\begin{array}{c}\text { Drainage } \\
\text { removed }\end{array}$ & $\begin{array}{c}\text { Hospital } \\
\text { stay }\end{array}$ \\
$\mathrm{P}$ & 0.041 & $<0.001$ & $<0.001$ & 0.022 & 0.036 & 0.022 & $<0.001$ & 0.001 \\
\hline
\end{tabular}




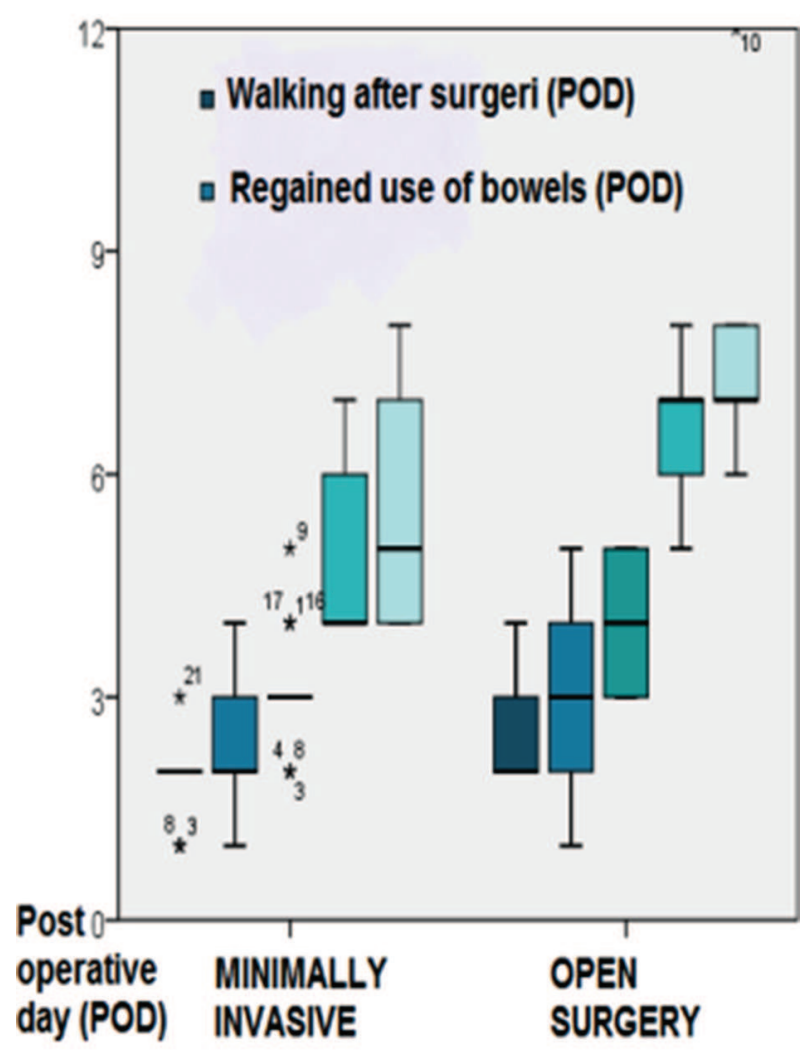

Figure 4. Walking time and regained use of bowels in minimally invasive and open surgery group

ly earlier than the open surgery group (Fig. $4 \& 5$ ). Hospital stay and nutrition supply were significantly shorter in the CRCm group than in the CRCk group, which is shown in Tabl. 2. Postoperative complication rates did not differ between the two groups.

There was no significant difference in the preoperative immunological results between the minimally invasive group and the conventional group.

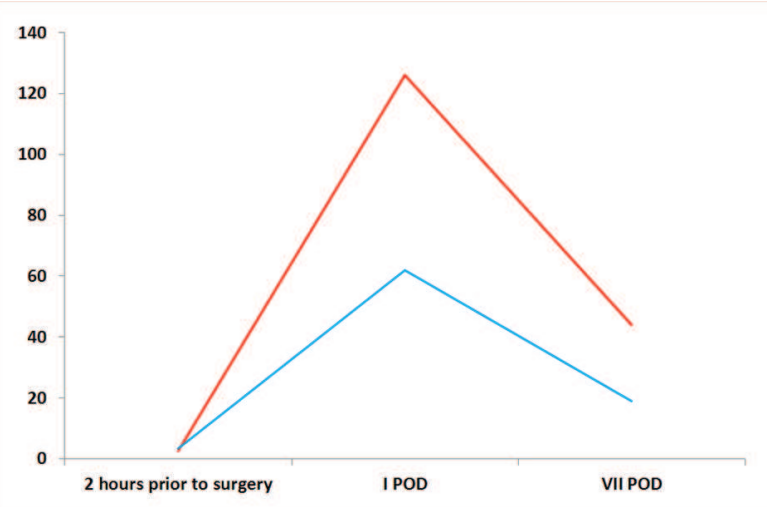

Figure 6. CRP levels in minimally invasive and open surgery group

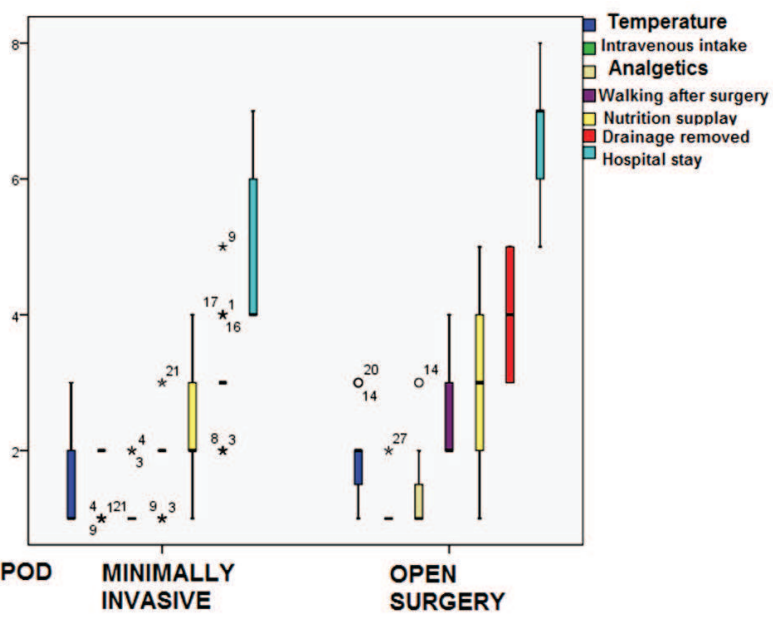

Figure 5. Temperature, intravenous intake, analgetics, walking after surgery, nutrition supply, drainage removed, hospital stay in minimally invasive and open sur-

gery group

CRP serum levels were increased on I POD in two surgical groups. The increase was significantly lower in the $\mathrm{CRCm}$ group on I POD $(\mathrm{P}=0.05)$. This ratio maintained for 7 days after surgery (Fig. 6).

24 hours after the surgery there was a significant increase in the leukocyte count and the granulocyte percentages in the CRCk group compared with the CRCm group, this ratio was maintained on VII POD.

Postoperative circulating total lymphocyte counts were decreased on I and VII POD in the two CRC groups. In the minimally invasive group the decrease was significantly lower and it returned to preoperative levels (Fig. 7). The reduction of $\mathrm{CD} 8+$ counts was less in CRCm compared with CRCk on I $\mathrm{POD}(\mathrm{P}=0.0004)$.

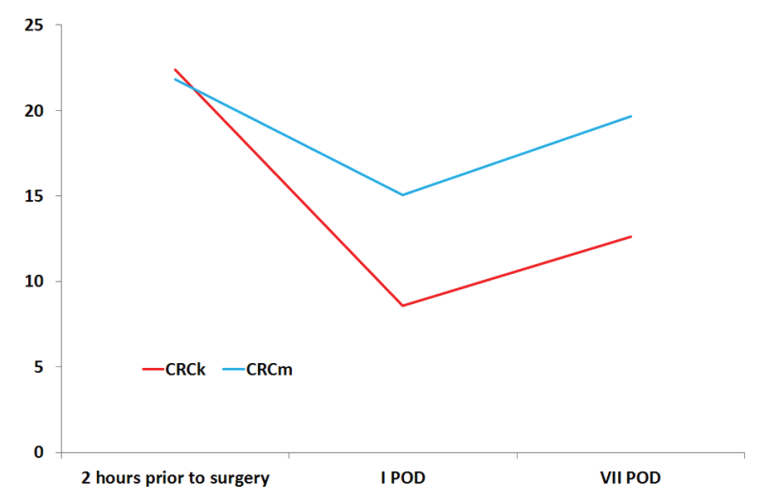

Figure 7. Total lymphocyte counts in minimally invasive and open surgery group 
Vasil Kyosev, Elena Vikentieva, Dora Popova et al.

Total protein and albumin, activated monocyte (CD 163+), eosinophiles and the percentage of monocytes were significantly decreased in the conventional group compared with the minimally invasive group on the first postoperative day. Serum levels returned near the preoperative value in the $\mathrm{CRCm}$ group on VII POD.

NK cell activity decreased slightly after surgery, and showed no significant difference when comparing CRCm with CRCk patients (Fig. 8). HLA-DR expression by monocytes was reduced after surgery in both groups, but levels returned to normal on VII POD in the CRCm group compared to CRCk (Fig. 9).

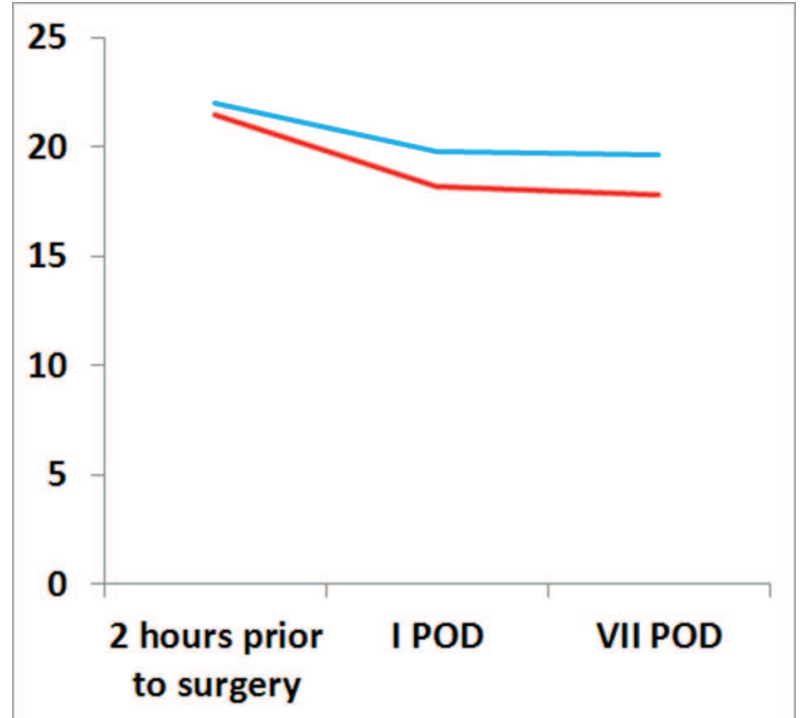

Figure 8. NK cell activity in minimally invasive and open surgery group

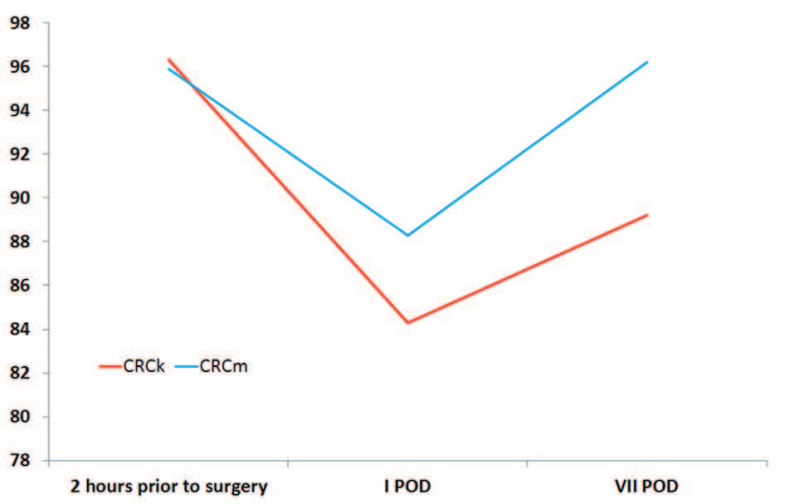

Figure 9. HLA-DR expression on monocytes in minimally invasive and open surgery group

\section{DISCUSSION}

The acute-phase response (APR) is important and necessary component of the immunological function. C-reactive protein (CRP) is the most extensively studied APR protein following trauma and surgery; it is a dependable marker for APR. CRP levels usually rise approximately $4 \pm 12 \mathrm{~h}$ after operation and peak at $24 \pm 72 \mathrm{~h}$, thereafter remaining raised for about 2 weeks (12). Postoperative CRP levels are significantly lower during the first 2 days after minimally invasive colorectal surgery than after open colorectal resections (13).

The phagocytic and chemotactic activity of neutrophilic granulocytes, which play a key role in host defence, are reduced after minimally invasive and open surgery (14). This impaired phagocytosis is possibly due to serum factors rather than an intrinsic neutrophilic defect. Several studies have evaluated the total leukocyte count and specific leukocyte populations and subpopulations following minimally invasive and open surgery, and have demonstrated a significant increase in overall peripheral leukocyte numbers following open, but not minimally invasive procedures (15). Significantly less activation, preserved serum factors and granulocytes functions all correlate with the clinical observation of fewer postoperative complications and faster recovery following minimally invasive surgery.

Monocytes also play an important role in the recognition and processing of foreign antigen, thereby helping to present the antigen to the leukocytes. The human leukocyte antigen (HLA)-DR (major histocompatibility protein class II) antigen, expressed on the surface of the monocyte \pm macrophage, is critical in this process. A significant reduction in HLADR expression has been reported after open colorectal resections, but not after minimally invasive (16).

Peripheral lymphocytes are the effectors of cellular immunity. When the host is exposed to surgical stress, the number of granulocytes increases, whereas the number of lymphocytes starts decreasing in peripheral blood. However, depressed NK cellular immunity occurs after surgical stress and this may reduce the resistance to viable tumour cells. A reduction in NK cell numbers following open and minimally invasive surgery was found. However, the reduction was less after the latter on the first postoper- 
ative day, with no advantage for the minimally invasive approach (17).

Colorectal surgery is associated with significant suppression of the overall immune status. Furthermore, the magnitude of this suppression appears to be proportional to the length of the wound used to access the peritoneal cavity. Possibly, for this reason, laparoscopic approaches are associated with less overall disturbance of the systemic immune function (17).

Cell-mediated immunity is also believed to influence postoperative tumor growth. Significantly less growth of extra-abdominal tumour following minimally invasive compared with open surgery was observed in immunocompetent mice. However, the tumor grew much faster, and the difference between minimally invasive and open surgery was lost, in an athymic mice model (18).

\section{CONCLUSIONS}

Minimally invasive colorectal cancer resection is a technically feasible option, with comparable results in terms of oncologic clearance, lesser degrees of tissue injury, surgical metabolic stress, and immunosuppressive response to conventional open surgery.

Decreased HLA-DR expression by monocytes in both groups, taking place on the first POD, reflects impaired antigen-presenting patients capacity. Indexes of CD64 expression by granulocytes are increased following surgery in two groups, but the minimally invasive group increase was significantly lower and correlated to faster recovery in the postoperative period.

Patients undergoing minimally invasive colorectal resections demonstrated improved clinical recovery and shorter hospital stay than patients undergoing open surgery.

\section{REFERENCES}

1. Ivanov P. Laparoscopic colorectal resections at malignant and benignant diseases of colon and rectum. PhD Theses. Sofia. 2014. (in Bulgarian).

2. Meyerhardt JA, Mayer RJ (2005) Systemic therapy for colorectal cancer. New Engl J Med 352(5):476-487
3. Weitz J, Koch M, Debus J, Hohler T, Galle PR, Büchler MW (2005) Seminar: colorectal cancer. Lancet 365:153-165

4. Lennard TW, Shenton BK, Borzotta A, Donnelly PK, White M, Gerrie LM, Proud G, Taylor RM (1985) The influence of surgical operations on components of the human immune system. Br J Surg 72(10):771-776

5. Biffl WL, Moore EE, Moore FA, Peterson VM (1996) Interleukin-6 in the injured patient. Marker of injury or mediator of inflammation? Ann Surg 224(5):647-664

6. Weissman C (1990) The metabolic response to stress: an overview and update. Anesthesiology 73(2):308-327

7. Reza MM, Blasco JA, Andradas E, Cantero R, Mayol J (2006) Systematic review of laparoscopic versus open surgery for colorectal cancer. Br J Surg 93(8):921-928

8. Jacobs M, Verdeja JC, Goldstein HS (1991) Minimally invasive colon resection (laparoscopic colectomy). Surg Laparosc Endosc 1 (3):144-150

9. Allendorf JD, Bessler M, Whelan RL, Trokel M, Laird DA, Terry MB, Treat MR (1997) Postoperative immune function varies inversely with the degree of surgical trauma in a murine model. Surg Endosc 11(5):427

10. Hewitt PM, Ip SM, Kwowk SPY, Somers SS, Li K, Leung KL, Lau WY, Li AKC (1998) Laparoscopic-assisted vs. open surgery for colorectal cancer: comparative study of immune effects. Dis Colon Rectum 41(7):901-909

11. Ordemann J, Jacobi CA, Schwenk W, Stosslein R, Muller JM (2001) Cellular and humoral inflammatory response after laparoscopic and conventional colorectal resections. Surg Endosc 15 (6):600-608

12. Ohzato H, Yoshizaki K, Nishimoto N, Ogata A, Tagoh $\mathrm{H}$, Monden $\mathrm{M}$ et al. Interleukin- 6 as a new indicator of inflammatory status: detection of serum levels of interleukin- 6 and C-reactive protein after surgery. Surgery 1992; 111: 201-9.

13. Kuntz C, Wunsch A, Bay F, Windeler J, Glaser F, Herfarth C. Prospective randomized study of stress and immune response after laparoscopic vs conventional colonic resection. Surg Endosc 1998; 12: 963-7.

14. Vittimberga FJ Jr, Foley DP, Meyers WC, Callery MP. Laparoscopic surgery and the systemic immune response. Ann Surg 1998; 227: 326-34. 
15. Brune IB, Wilke W, Hensler T, Feussner H, Holzmann B, Siewert JR. Normal T lymphocyte and monocyte function after minimally invasive surgery. Surg Endosc 1998; 12: 1020-4.

16. Cristaldi M, Rovati M, Elli M, Gerlinzani S, Lesma L, Balzarotti L et al. Lymphocytic subpopulation changes after open and laparoscopic cholecystectomy: a prospective and comparative study on 38 patients. Surg Laparosc Endosc 1997; 7: 255-61.

17. Allendorf JD, Bessler M, Whelan RL, Trokel M, Laird DA, Terry MB et al. Better preservation of immune function after laparoscopic-assisted vs open bowel resection in a murine model. Dis Colon Rectum 1996; 39(Suppl): S67-72.

18. Allendorf JD, Bessler M, Horvath KD, Marvin MR, Laird DA, Whelan RL. Increased tumor establishment and growth after open vs laparoscopic surgery in mice may be related to differences in postoperative T-cell function. Surg Endosc 1999; 13: 233-5.

19. Joris J, Cigarini I, Legrand M, Jacquet N, De Groote D, Franchimont $\mathrm{P}$ et al. Metabolic and respiratory changes after cholecystectomy performed via laparotomy or laparoscopy. Br J Anaesth 1992; 69: 341-5. 